\title{
Латеральные наноструктуры Ga(In)AsP как часть оптической системы фотопреобразователей на основе GaAs
}

\author{
(С) Л.Б. Карлина ${ }^{1}$, А.С. Власов ${ }^{1}$, М.3. Шварц ${ }^{1}$, И.П. Сошников ${ }^{1,2}$, И.П. Смирнова ${ }^{1}$, \\ Ф.Э. Комисаренко ${ }^{3}$, А.В. Анкудинов ${ }^{1}$ \\ ${ }^{1}$ Физико-технический институт им. А.Ф. Иоффре Российской академии наук, \\ 194021 Санкт-Петербург, Россия \\ ${ }^{2}$ Санкт-Петербургский Академический университет, \\ 194021 Санкт-Петербург, Россия \\ ${ }^{3}$ Университет ИТМО, \\ 197101 Санкт-Петербург, Россия \\ E-mail: karlin@mail.ioffe.ru
}

Поступила в Редакцию 23 июля 2019 г.

В окончательной редакции 29 июля 2019 г.

Принята к публикации 29 июля 2019 г.

Впервые рассмотрена возможность использования латеральных наноструктур $\mathrm{Ga}(\mathrm{In}) \mathrm{AsP}$, выращенных каталитическим методом в квазизамкнутом объеме из паров фосфора и индия на поверхности GaAs $(100)$ в качестве антиотражающего покрытия для фотоэлектрических приборов. Показано, что при фиксированной температуре роста возможно управление морфологией поверхности путем изменения времени роста. Морфологию поверхности исследовали методами растровой электронной и атомно-силовой микроскопии. Показана связь структуры поверхности с ее антиотражательными свойствами в диапазоне 400-800 нм. Использование данного покрытия в фотоэлементах на основе GaAs показало существенное увеличение внешнего квантового выхода фотопреобразователей.

Ключевые слова: наноструктуры, каталитический рост, $\mathrm{Ga}(\mathrm{In}) \mathrm{AsP}$, антиотражающее покрытие.

DOI: 10.21883/FTP.2019.12.48632.9218

\section{1. Введение}

Системы, снижающие оптические потери фотопреобразователей и оптоэлектронных устройств на основе соединений $\mathrm{A}^{\mathrm{III}} \mathrm{B}^{\mathrm{V}}$ и кремния, активно изучаются на протяжении многих лет [1]. Многообразие подходов с использованием просветляющих диэлектрических покрытий и(или) текстурированием материала поверхности самого элемента позволяет существенно расширить технологические возможности повышения их эффективности.

Одним из способов уменьшения отражения является просветление материала, заключающееся в создании на поверхности структуры оптически прозрачной тонкой пленки. Принцип ее действия основан на взаимном гашении интерферирующих друг с другом лучей, которые отражаются от наружной и внутренней сторон пленки. Однослойные просветляющие покрытия имеют серьезный недостаток: они могут быть использованы только для относительно узкого диапазона длин волн и углов падения. Этот диапазон можно расширить, применяя многослойные покрытия. Принцип действия таких покрытий тот же, что и в случае однослойных, - взаимное интерференционное гашение двух или нескольких волн, отраженных от разных границ раздела между слоями. Альтернативой многослойным просветляющим покрытиям могут служить слои с непрерывно меняющимся коэффициентом преломления. Применение таких покрытий позволяет достичь низких значений коэффициента отражения в широком спектральном диапа- зоне. Однако и такие покрытия имеют свои недостатки, среди которых несоответствие температурных коэффициентов расширения получаемых слоев и адгезионная прочность.

Современный подход состоит в формировании наноструктурированных поверхностей, имеющих выступы и углубления конической или параболоидной формы с характерными размерами в сотни нанометров, т.е. соизмеримые с длинами волн видимого света. Такой тип антиотражающих поверхностей проявляет так называемый эффект глаза ночной бабочки (moth eye effect), для которого характерно снижение оптического отражения во всем диапазоне видимого спектра и в широком интервале углов облучения поверхности. Формирование таких поверхностей можно осуществлять различными способами, включая сухое и мокрое травление фронтальной поверхности элементов, используя нанесение различных полимерных покрытий, выращивание дополнительных слоев методами химического осаждения из металлоорганических соединений (CVD), молекулярно-лучевой эпитаксии (MBE) и др. [1-6]. Одним из перспективных способов формирования текстурированных антиотражающих покрытий является выращивание наноструктур на активной поверхности элементов самой разной геометрии и разного состава методами каталитического и самокаталитического роста.

Такой подход представлен, например, в работе [7], где показано, что антиотражающее покрытие на основе нанопроводов $\mathrm{GaP}$ является перспективным материалом для солнечных элементов и светодиодов. 
Наши предыдущие исследования показали, что, используя простой метод каталитического роста из паров фосфора и индия, можно получить латеральные слои $\mathrm{Ga}(\mathrm{In}) \mathrm{AsP}$ различной геометрии, которые могут рассматриваться в качестве антиотражающих поверхностей [8]. Целью данной работы является экспериментальное определение влияния температурновременны́х условий выращивания латеральных наноструктур $\mathrm{Ga}(\mathrm{In}) \mathrm{AsP}$ на коэффициент отражения и характеристики фотопреобразователей на основе GaAs.

\section{2. Методика эксперимента}

В качестве подложек использовались полированные пластины GaAs (100) качества „ері-ready“. Формирование антиотражающего покрытия, состоящего из латеральных наноструктур $\mathrm{Ga}(\mathrm{In}) \mathrm{AsP}$ различной толщины и с различной морфологией, осуществлялось методом каталитического роста в квазизамкнутом объеме [8].

Исследование поверхностной морфологии полученных образцов проводилось методом растровой электронной микроскопии (РЭМ) на микроскопе Carl Zeiss SUPRA25 при ускоряющем напряжении 5 кB, а также методом атомно-силовой микроскопии с кантилеверами типа HA_NC в контактной моде на установке NT-MDT Integra-Aura.

Спектры рамановского рассеяния света были получены в геометрии обратного рассеяния в поляризации $z(x y) z$ на установке со спектральным разрешением не хуже $1 \mathrm{~cm}^{-1}$. Для возбуждения использовался одночастотный непрерывный лазер с длиной волны 532 нм.

Спектральные зависимости коэффициента полного (интегрального) отражения исследовались с использованием интегрирующей сферы UPB-150-ART при положении исследуемого образца под углом $8^{\circ}$ к падающему световому потоку. Регистрация спектра отражения обеспечивалась волоконным спектрорадиометром AvaSpec 2048 (Fiber Optic Spectrometer), подключенным на выходной порт сферы.

Формирование $p-n$-переходов в контрольных структурах и структурах с антиотражающими покрытиями на основе наноструктур $\mathrm{Ga}(\mathrm{In}) \mathrm{AsP}$ выполнено диффузией цинка из локального источника по методике, описанной ранее [9]. Спектральные характеристики полученных образцов и спектры отражения измерялись стандартными методами [10].

\section{3. Результаты и обсуждение}

Исследования, проведенные нами ранее [8], показали, что, изменяя температурно-временно́й режим роста латеральных наноструктур, можно получать различную морфологию их поверхности. На рис. 1 представлены электронно-микроскопические изображения поверхности образцов, измеренные в двух проекциях: нормальной и под углом $45^{\circ}$. Образцы получены при температуpe $T=630^{\circ} \mathrm{C}$ и различаются временем отжига: образец \#1 - 20 мин, образец \#2 - 60 мин.
Как видно из рис. 1, поверхности имеют случайные шероховатости с характерными поперечными размерами 100-200 нм. При этом часовой отжиг в парах In, P приводит к визуально более однородному рисунку поверхности. Для анализа шероховатости поверхности образцы
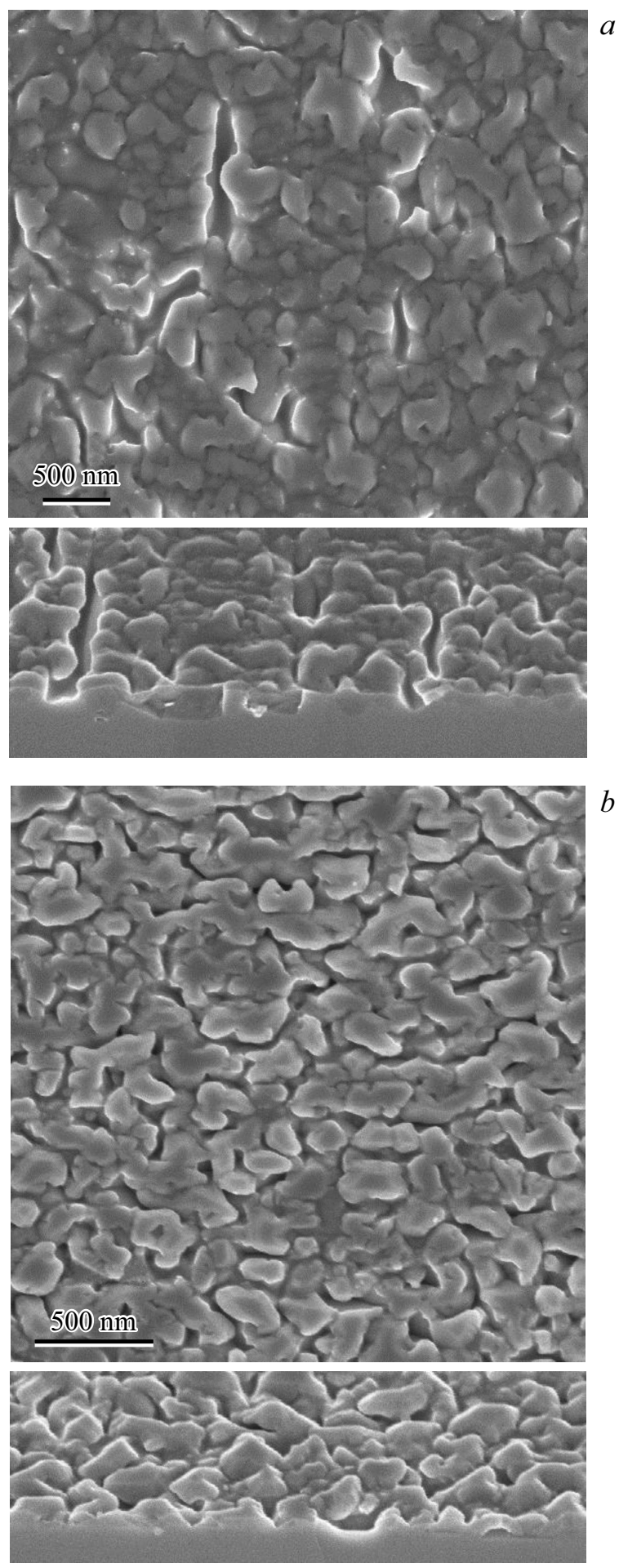

Рис. 1. Электронно-микроскопическое изображение поверхности латеральных наноструктур, полученных при различных условиях: $a-630^{\circ} \mathrm{C}, 20$ мин (образец $\left.\# 1\right), b-630^{\circ} \mathrm{C}, 60$ мин (образец \#2). 


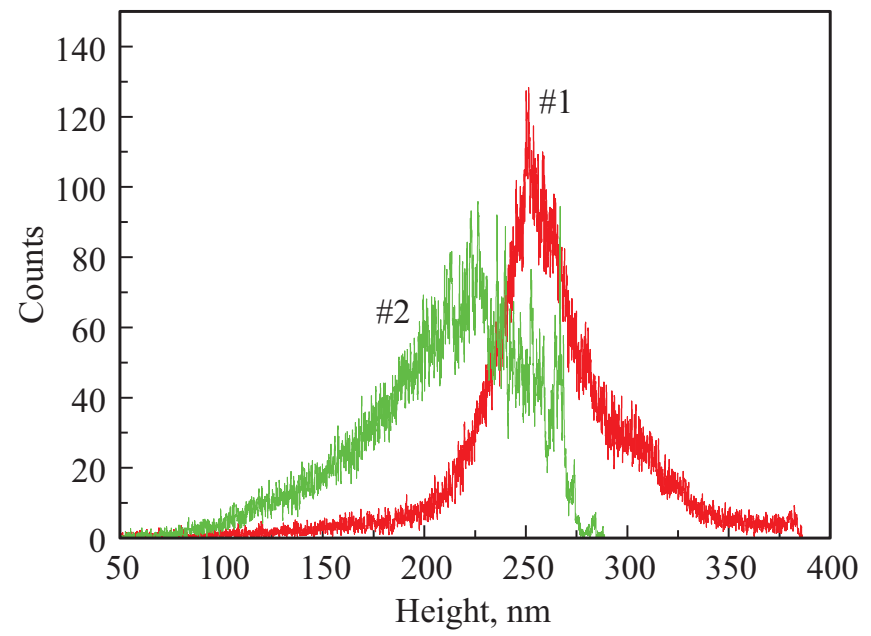

Рис. 2. АСМ-гистограммы распределения высоты для образцов \#1 (20 мин), \#2 (60 мин).

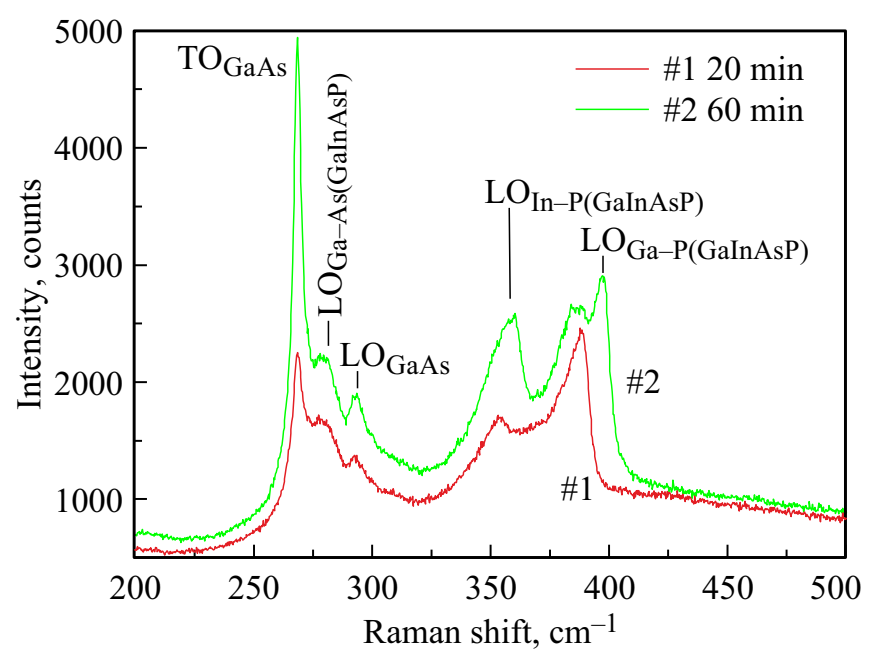

Рис. 3. Спектры рамановского рассеяния образцов \#1 (20 мин), \#2 (60 мин).

исследовались с помощью атомно-силового микроскопа. На рис. 2 представлены гистограммы распределения высоты для двух образцов из рис. 1. Видно, что увеличение времени роста приводит к расширению гистограммы при одновременном уменьшении предельного разброса высоты, т.е. шероховатость становится более равномерной и заполняет всю поверхность образца. Также на гистограмме образца \#2 (60 мин) видно появление пиков на определенных значениях высот. Присутствие таких пиков связано с формой получаемых фасет, имеющих зачастую плоскопараллельную вершину.

Состав текстурированного покрытия также изменяется по мере увеличения времени роста. На рис. 3 представлены спектры рамановского рассеяния тех же образцов. Спектр образца \#1 (20 мин) содержит колебания типов $\mathrm{Ga}-\mathrm{P}$, In-P и $\mathrm{Ga}-\mathrm{As}$, соответствующих твердому раствору GaInAsP. Также в спектре видны поперечные (TO) и продольные (LO) оптические колебания типа $\mathrm{Ga}-\mathrm{As}$, соответствующие подложке. Сo- держание фосфора в данном твердом растворе можно оценить как $\sim 50 \%$. В спектре образца \#2 наблюдается значительное усиление полосы при $355 \mathrm{~cm}^{-1}$ (соответствующей продольным колебаниям связи типа In-P), ее сдвиг в сторону бо́льших энергий, что может свидетельствовать о снижении концентрации атомов мышьяка в твердой фазе, а также появление полосы при $397 \mathrm{~cm}^{-1}$, соответствующей продольным колебаниям связей типа $\mathrm{Ga}-\mathrm{P}$. Таким образом, можно заключить, что продолжительный отжиг приводит к появлению еще одной фазы твердого раствора с повышенным содержанием фосфора (до 70\%) и индия по сравнению с образцом \#1. Таким образом слой твердого раствора, полученный в выбранных условиях, является непрямозонным с шириной запрещенной зоны $>2$ эВ, что хорошо подходит для использования в качестве просветляющего текстурированного покрытия для фотопреобразователей.

При выбранной нами температуре увеличение времени роста приводит к изменению отношения содержания $\mathrm{As} / \mathrm{Ga}$ и $\mathrm{P} / \mathrm{Ga}$ в капле катализатора. Жидкая фаза катализатора полностью расходуется, и дальнейший рост происходит по другому механизму, уже без ее присутствия, т.е. по механизму пар-твердое тело, что способствует полицентрическому зарождению новой фазы. Увеличивается содержание индия и фосфора в твердом растворе. По всей видимости, это связано с тем, что по мере увеличения плотности и толщины текстурированного слоя сокращается процесс диффузии атомов GaAs в зону роста, приводя к изменению механизма формирования слоя.

На рис. 4 представлены спектры полного отражения для двух выбранных образцов. В качестве референтного представлен также спектр отражения подложки GaAs. Наибольшие изменения коэффициента отражения в видимом и ближнем инфракрасном диапазонах на-

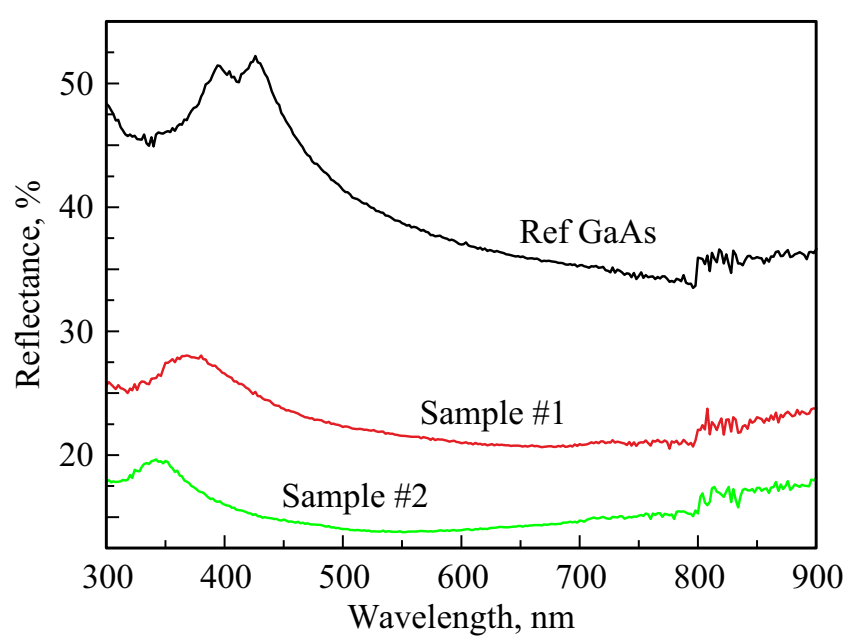

Рис. 4. Интегральный коэффициент отражения для образцов \#1, \#2 с латеральными наноструктурами, полученными при различных температурно-временны́х условиях $-T=630^{\circ} \mathrm{C}$, 20 (\#1) и 60 мин (\#2). Для сравнения приведен коэффициент отражения GaAs. 


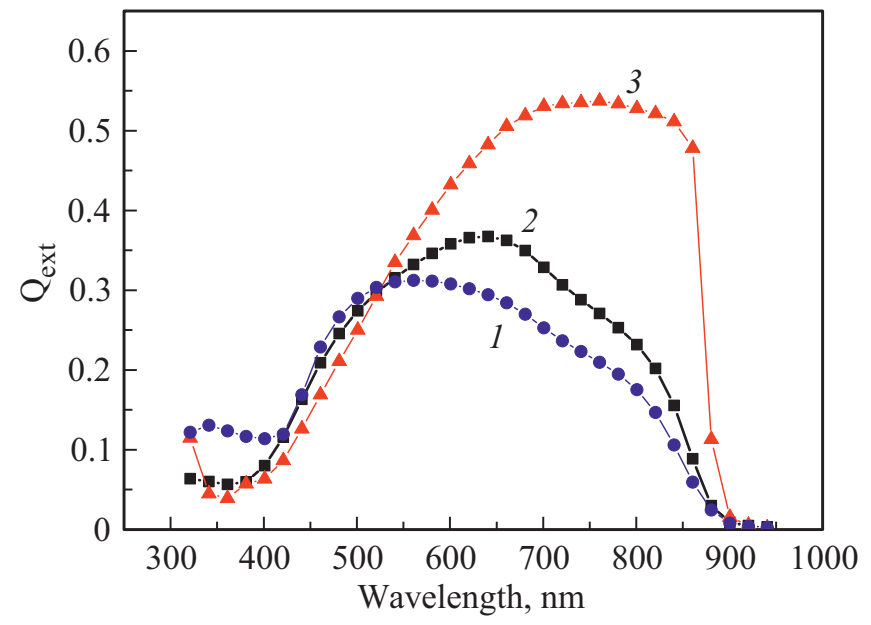

Pис. 5. Спектральные характеристики внешнего квантового выхода $\left(Q_{\text {ext }}\right)$ фотоэлементов на основе $\mathrm{GaAs}$ с различной поверхностью: 1 - контрольный образец, 2, 3 - GaAs c латеральной наноструктурой $\mathrm{Ga}(\mathrm{In}) \mathrm{AsP}$ (длительность роста 20 и 60 мин соответственно).

блюдаются для образца \#2 (60 мин), что коррелирует с увеличенной шероховатостью, обсуждавшейся выше.

С целью проверки применимости предложенного нами способа формирования антиотражающего покрытия для фотопреобразователей были сделаны макеты солнечных элементов на основе GaAs. Режимы диффузии выбирались таким образом, чтобы обеспечить одинаковую глубину залегания $p-n$-перехода в контрольном образце и в образцах с наноструктурированной поверхностью. Как видно из рис. 5, использование латеральных наноструктур обеспечивает значительное увеличение квантового выхода фотоответа в спектральном диапазоне 600-850 нм. Значения тока короткого замыкания при измерении с источником AM1.5D составили $7.3 \mathrm{MA} / \mathrm{cm}$, для образца без обработки 8.48 и $13.0 \mathrm{MA} / \mathrm{cm}^{2}$ для образца \#1 и образца \#2 соответственно.

\section{4. Заключение}

Исследована возможность создания антиотражающих покрытий на поверхности арсенида галлия с использованием каталитического роста латеральных наноструктур $\mathrm{Ga}(\mathrm{In}) \mathrm{AsP}$.

Изучение морфологии полученных слоев показало возможность изменения величины коэффициента отражения в видимой области спектра путем изменения времени их роста при заданной температуре. Наблюдаемое изменение механизма роста наноструктур от пар-жидкость-твердое к механизму роста пар-твердое сопровождается изменением морфологии и формированием текстуры с эффектом просветления. Фотоэлементы на основе GaAs c антиотражающим покрытием $\mathrm{Ga}(\mathrm{In}) \mathrm{AsP}$ на основе латеральных наноструктур показали значительное увеличение внешнего квантового выхода.

\section{Конфликт интересов}

Авторы заявляют, что у них нет конфликта интересов.

\section{Список литературы}

[1] Progress in Advanced Structural and Functional Materials Design, ed. by T. Kakeshita (Springer, 2013).

[2] A. Bahrami, S. Mohammadnejad, N.J. Abkenar, S. Soleimaninezhad. Int. J. Renew. Energy Res., 1, 79 (2013).

[3] M.K. Hedayati, M. Elbahri. Materials, 9, 497 (2016).

[4] Y-J. Lee, D.S. Ruby, D.W. Peters, B.B. McKenzie, W.P. Hsu. Nano Lett., 8 (5), 1501 (2008).

[5] S. Chattopadhyay, Y.F. Huang, Y.J. Jen, A. Ganguly, K.H. Chen, L.C. Chen. Mater. Sci. Engin. Rep., 69, 1 (2010).

[6] J.W. Leem, J.S. Yu, Y.M. Song, Y.T. Lee. Solar Energy Mater. Solar Cells, 95, 669 (2011).

[7] S.L. Diedenhofen, G. Vecchi, R.E. Algra, A. Hartsuiker, O.L. Muskens, G. Immink, E.P.A.M. Bakkers, W.L. Vos, J.G. Rivas. Adv. Mater., 21, 973 (2009).

[8] Л.Б. Карлина, А.С. Власов, И.П. Сошников, И.П. Смирнова, Б.Я. Бер, А.Б. Смирнов. ФТП, 52 (10), 1244 (2018).

[9] L.B. Karlina, A.S. Vlasov, B.Y. Ber, D.Y. Kazantsev. J. Cryst. Growth, 432, 1338 (2015).

[10] M.Z. Shvarts, A.E. Chalov, E.A. Ionova, V.R. Larionov, D.A. Malevskiy, V.D. Rumyantsev, S.S. Titkov. Proc. 20th EUPVSEC (Barcelona, 2005) p. 278.

Редактор Л.В. Шаронова

\section{$\mathrm{Ga}(\mathrm{In}) \mathrm{AsP}$ lateral nanostructures as optical component of GaAs based photovoltaic}

\author{
L.B. Karlina ${ }^{1}$, A.S. Vlasov ${ }^{1}$, M.Z. Shvarts ${ }^{1}$, \\ I.P. Soshnikov ${ }^{1,2}$, I.P. Smirnova ${ }^{1}$, \\ F.E. Komissarenko ${ }^{3}$, A.V. Ankudinov ${ }^{1}$ \\ ${ }^{1}$ loffe Institute, \\ 194021 St. Petersburg, Russia \\ 2 St. Petersburg Academic University, \\ 194021 St. Petersburg, Russia \\ 3 ITMO University, \\ 197101 St. Petersburg, Russia
}

\begin{abstract}
The possibility of lateral $\mathrm{Ga}(\mathrm{In}) \mathrm{AsP}$ nanostructures grown by the catalytic method in a quasi-closed volume from phosphorus and indium vapors on the GaAs (100) surface as an antireflection coating for photovoltaic devices is considered for the first time. It is shown that at fixed growth temperature, it is possible to control the surface morphology by changing the growth time. The surface morphology was investigated by scanning electron and atomic force microscopy. The dependence of surface reflection coefficient in the range of $400-800 \mathrm{~nm}$ on the surface structure is shown. The use of such coating in GaAsbased photocells demonstrated a significant increase in the external quantum yield of photoconverters.
\end{abstract}

